\section{Japanese Production}

The researches conducted at Mysore have been published $^{2-10}$ in the form of short notes and papers which have appeared during the past three years. Numerous popular articles and pamphlets have also been published. During 1952, the Japanese manufacturers, who have also been keen on the search for rice substitutes, started production, using blends of potato starch, wheat flour and rice flour for their composition. The underlying principles are practically the same as those of the process adopted by the Mysore workers. The Japanese have also adopted the same English name, 'synthetic rice', for their product, and the Japanese name is 'zin-zomai'. It should be said to the credit of the Japanese that they were quick in taking up the manufacture. During 1952-53, the reported production is stated to have been about 100,000 tons. The price of the Japanese product appears to be fairly high; but there is no doubt that it will eventually be reduced. Further improvement in nutritive value is needed, and this can be achieved by adding a concentrated proteinaceous material along the lines indicated by the Mysore workers.

The relative chemical compositions of some of the rice substitutes as compared with natural rice is given in Table 1 .

\section{Outlook for the Future}

Judging from the present trends, there is every indication that the rice production in the east and south-east Asian countries will not be able to cope with the increasing demands of the fast-growing population. A product like synthetic rice is bound to find a growing demand, and in the course of the next few years we may reasonably expect to see the production rise to a few million tons per annum. With further improvements in the composition and the technology of processing, better and cheaper grains could be produced. The nutritive values of the products can also be maintained at a distinctly higher level than that of natural rice.

There are already a number of rice substitutes on the world's market. They are made from different raw materials and they have varied compositions. Most of them are being marketed under proprietary names and selling on their own merits. It is expected that, in course of time, several more such products will be marketed. It will soon be necessary to discuss the composition of such products and to lay down specifications on an international basis; the Food and Agriculture Organization can usefully take the initiative in this direction.

There are three broad lines of food production. The first one is that of increasing the production from land, water and other sources. Improved methods can easily raise the world's production by 25 or even 50 per cent, though it will be extremely difficult to ensure a uniform application of such methods all over the world. The second method is that of converting the vast and abundant sources of second-grade food materials, by suitable blending, into first-class articles of food. Production of synthetic rice will come in this category. Products like sugar from cellulose, food yeast, food-stuffs from seaweeds and other algae will also come in the same category. The possibilities in this direction are very considerable. The third method, which is still a dream of chemists, is that of synthesis from elementary materials. Unlike the fixation of nitrogen, the fixation of atmospheric carbon dioxide is going to be rather difficult because of the low concentration of this gas in the atmosphere. For a long time to come, the world may have to depend on the processing of coarse and low-grade food materials, which are fortunately still abundant, and their conversion into first-grade articles of food. Production of synthetic rice is a beginning in this direction; but bigger and more important developments are bound to follow in the years to come.

${ }^{1}$ Cent. Food Tech. Res. Inst., Mysore (Pub.), "Food and Population" and "Development of Food Industries", pp. 357, tllus. (Mysore, 1952). 'Subrahmanyan, V., Rama Rao, G., and Swaminathan, M., J. Sci.
Indust. Res., B, 9, 259 (1950).

${ }^{3}$ Bhatia, D. S., Indian Coffee, 16 (1), 6 (1952).

${ }^{4}$ Subrahmanyan, V., Bull. Cent. Food Technol. Res. Inst., 2, 48 (1952).

- Subba Rao, G. N., Bains, G. S., Bhatia, D. S., and Subrahmanyan, V., Trans. Amer. Assoc. Cereal Chem., 11 (2), 167 (1953).

- Subrahmanyan, V., Bull. Cent. Food Technol. Res. Inst., 2, 239 (1953).

'Subrahmanyan, V., Bhatia, D. S., Bains, G. S., Swaminathan, M., and Raghunatha Rao, Y. K., Bull. Cent. Food Technol. Res. Inst. (in the press).

- Bains, G. S., Bhatia, D. S., Subba Rao, G. N., and Subrahmanyan, V., ibid. (in the press).

- Subrahmanyan, V., Kuppuswamy, S., Rama Rao, G., Swaminathan, M., and Bhatia, D. S., ibid. (in the press).
Whahm,

${ }^{10}$ Subrahmanyan, V., Kuppuswamy, S., Rama Rao, G., Swaminathan, M., and Bhatia, D. S., ibid. (in the press).

\section{RHEOLOGY IN MECHANICAL ENGINEERING}

R HEOLOGY is regarded by some as a specialized activity concerned with the description of the response to mechanical stress of those categories of matter the behaviour of which cannot, even approximately, be described as Newtonian flow or Hookean deformation. Others view the subject more broadly as that branch of the science of applied mechanics which is concerned with the deformation and flow of matter generally. The membership of the British Society of Rheology embraces both those who specialize in the subject and those chemists, physicists and engineers, mainly engaged in applied science, whose work involves a knowledge of deformation or flow of matter and who find in the Society common ground for the development of this interest. It is to these latter that the recent conference of the Society held at the Mechanical Engineering Research Labors. tory (Department of Scientific and Industrial Research), East Kilbride, during June 10-12 will have had the most appeal.

This Laboratory, which has assumed responsibility for a large part of the research formerly pursued in the Engineering Division of the National Physical Laboratory, is organized in seven divisions as follows : properties and strength of materials ; mechanics of solids, stress analysis and vibration; mechanics of fluids, including hydraulic machinery; lubrication, wear and corrosion; mechanisms and engineering metrology; mechanics of formation and machine shaping of materials; heat transfer and applied thermodynamies. It will be apparent from this list of activities that the deformation and flow of matter enters very much into the work of the Laboratory, and the opportunity afforded to participants to inspect work in progress was a valuable feature of the conference.

In view of the importance of metals as materials of construction for machinery, it is not surprising that the predominant interest in the conference was the 
flow of metals. Thus the first paper, by Dr. J. F. W. Bishop (East Kilbride), was on the relationship of certain properties of metals to their crystal structure. Phenomena associated with metals were divided into three classes-macroscopic, microscopic and atomic-and the relevance of investigations at one of these levels to phenomena associated with a different level was discussed. Dr. Bishop summarized the salient features of three types of lattice structure commonly occurring in metal crystals and described their mechanism of deformation, stressing those structures which are able to accommodate an arbitrary strain by relative sliding of atomic planes. Applications of the Bishop-Hill theory of crystal distortion as generalized for aggregates were described and discussed in relation to experimental evidence.

Mr. H. Ll. D. Pugh (East Kilbride), in his paper on current problems and experiments on time-independent plastic deformation, dealt with the fundamental plastic properties of materials, such as yielding under combined stress, hardening and the effects of hydrostatic pressure. In the absence of a general solution of the equations governing plastic flow, their simplification for the special cases of plane stress and plane strain is necessary to enable certain engineering problems to be attacked. Strip drawing, extrusion and certain machining operations resolve themselves into steady-state problems, while indentation becomes a yield stress problem. Theoretical and experimental results were compared for extrusion and for indentation with flat smooth rigid dies.

Mr. F. Ellis and Prof. H. Ford (Imperial College of Science and Technology, London) discussed strip rolling as a steady-state process. An approximate theory was outlined by Prof. Ford, who described subsidiary experiments to determine the yield stressstrain characteristics of the strip material. Coefficient of friction between roll and work was estimated from rolling experiments in which varying amounts of back tension had been applied. Mr. Ellis described experiments wherein the data required to plot the slip-line field were obtained from the measured distortion of a network of lines engraved on a surface lying in the plane of flow. This technique was complicated in its application to rolling by forces in the plane of the sheet which would cause two unattached sheets placed side by side to separate. The difficulty was overcome by a specially developed method whereby the edges of two sheets could be welded together after the reference lines had been engraved on them.

In contradistinction to the two previous contributions, which were directed towards the elucidation of situations wherein it was desired to cause flow as part of a manufacturing process, that by Dr. A. E. Johnson (East Kilbride) on the behaviour of metals under complex stress at high temperatures was concerned with the small unintentional flow or creep of metals used for the construction of boilers, turbines, etc., that are required to operate at high temperatures. Where such parts are subject to combined stresses, designers have previously been obliged to rely on experimental data obtained from simple stress tests and adjusted by doubtfully valid theory. Dr. Johnson described a comprehensive research into the complex stress, creep, plastic strain and relaxation properties of some typical technical materials. At lower stresses the materials were shown to follow the St. VenantVon Mises creep-rate relations and to remain isotropic; but at higher stresses the strained material becomes anisotropic, which necessitates modification of the equations.
Fatigue failure of metals may be regarded as a rupture rather than a flow phenomenon, but some work sponsored by the Mechanical Engineering Research Laboratory and described by Mr. N. Wadsworth (University of Bristol), in a paper on observations on onergy dissipation during high-speed fatigue tests, revealed the occurrence of an increasing number of slip bands during the progress of a fatigue test. During the early stages of a test, the rate of energy dissipation in the material fell to a low value and then increased until failure occurred. This increase was dependent on stress, and a strong correlation between this rate and fatigue life was revealed. Annealing at in. tervals during the test appeared to remove the effects of previous stressing on energy dissipation, but did not affect life. This threw doubt on the significance of the observed correlation, and $\mathrm{Mr}$. Wadsworth concluded with the suggestion that the first irreversible change leading to the formation of cracks must have occurred very early in the fatigue test.

A more general approach to rheological problems was represented by a contribution from Dr. P. Feltham (Standard Telecommunication Laboratories) on the laws of stress relaxation and creep in solids. Remarking on the qualitative similarity in the response of solids of widely different structures to applied stresses, particularly in creep and relaxation, Dr. Feltham sought an explanation in the nature of flow itself rather than in the study of detailed atomic or molecular structure. A given solid can be assumed to possess 'relaxation centres' having approximately the same heat of activation but, on account of variations such as shape and size, having different configurational entropies of activation. Assuming normal distribution of relaxation times it is possible to derive a relaxation curve common to many solids. Experimental data selected from published work relating to aluminium, rubber, plastics and ceramics were shown to be in good agreement with the theory. Dr. Feltham regards Nutting's Law as approximating to more general laws over sufficiently wide ranges of the variables to be of practical use in the presentation of experimental data.

The fact that mechanical engineering science is by no means confined to the behaviour of solids was exemplified by a paper by Mr. E. J. Le Fevre (East Kilbride) which dealt with some developments in the theory of viscosity. The importance of the viscosity of gases in the study of the transfer of heat by convection is obvious; but availability of experimental data covering this quantity over the range required is restricted, and discrimination is necessary in assessing its accuracy. Mr. Le Fevre showed how viscosity data relating to those fluids which satisfy the principle of corresponding states can be correlated in terms of reduced variables. It was shown that, with few exceptions, the viscosity of gases can be predicted within about 5 per cent from knowledge of the three critical constants. This result was considered relative to the kinetic theory and was shown to be deducible from combination of the Lennard-Jones and Devonshire theory of the critical state with the calculations of Kihara and Kotini. The Sutherland model was shown to be inconsistent with experiment.

Many problems of fluid motion in the mechanical and chemical engineering industries are amenable to solution by models, and Mr. W. J. Robinson (East Kilbride), in his paper on some fluid-motion problems, exemplified useful applications of this technique at the Mechanical Engineering Research Laboratory. Advantages are offered by substitution in a model of 
gases for liquids or vice versa. The conflicting requirements of the laws of similitude complicate the design of experiments, and a plea was made for the publication of more experimental data to provide a basis for evolution of rules to govern the 'scaling-up' of model performance. Increases in the duty required to bo undertaken by modern hydraulic machinery have caused a marked increase in the incidence of cavitation, and Mr. Robinson diseussed the influence of the properties of the liquid itself and the presence of nuclei on cavity collapse and noise. Methods for estimating flow losses with non-Newtonian liquids require development. The pumping of raw peat and measurement of the flow of blood to and from the human heart provoked a lively discussion.

Lubrication has been defined as the reduction of friction and wear between rubbing surfaces by interpolation of substances which offer resistance to the normal forces pressing the surfaces into contact and yet are capable of being deformed easily in a tangential direction. It is obvious that the rheological properties of lubricants are of interest to engineers concerned with running machinery, and Dr. F. T. Barwell (East Kilbride), in a contribution on lubrication from the rheological point of view, outlined some of the considerations governing boundary and hydrodynamic lubrication. Further understanding of the mechanism of wear is dependent, among other things, on an understanding of the rheological behaviour of material in the surface regions of components suffering damage. Examples were given of those forms of wear known as abrasion, scuffing and pitting, and the potentialities of radioactive tracer methods for the study of wear were discussed.

\section{THE ROYAL NETHERLANDS METEOROLOGICAL INSTITUTE (1854-1954)}

T

HIS decade is one of centenaries in the meteorological world, for official meteorological activities started in many countries around 1850. The Royal Netherlands Meteorological Institute, now at De Bilt near the town of Utrecht, was established in 1854 and colebrated its centenary this year on January 31. As part of the celebrations, a substantial memorial volume has been prepared*, in which the history of the Institute is portrayed in word and image.

Meteorology in the Netherlands did not start in 1854; there are many signs of earlier activity in the form of long series of observations, admirably compiled by Labrijn. As everywhere else in the world, these observations were made at universities, or by organizations and persons especially interested in meteorology; and looking at the state of affairs in 1854, one should realize that the famous American naval officer, Maury, prior to that year, had already collected many meteorological observations from oceanic areas.

In the Netherlands it was important for the development of the subject that Buys Ballot, chemist, mineralogist, mathematician and physicist, became fascinated by meteorological problems, and that he, in his position as university professor, created an

* Koninklijk Nederlands Meteorologisch Instituut 1354-1954. Pp. $469+74$ flgs. +4 coloured plates. ('s-Gravenhage: Staatsdrukkerij en Uitgeversbedrijf, 1954.) observatory in Utrecht. Late in 1853 Buys Ballot convinced the Government that "there was a future in the establishment of a Meteorological Institute" and early in 1854 his observatory was converted into the Koninklijk Nederlands Meteorologisch Instituut. Buys Ballot was the first director of the Institute and aimed very high. Translated freely, his programme was formulated by the words: "As a result of the methods we have adopted-namely, to collect observations from some well-selected points abroad and to study the deviations from the normals at these points - the Institute pursues a higher object than any other existing institute. Day after day it deals with the most important questions in meteorology, the solution of which was already some years ago vaguely indicated by Dove for monthly periods. Utrecht will become the central observatory for Europe. Already nowadays the weather and its changes over the greater part of Western Europe are being closely followed and studied".

The early period of Buys Ballot's directorship was one of great activity. It was the time of Dove in Germany, Espy in the United States, FitzRoy in Britain and LeVerrier in France. It was also the time in which meteorologists suddenly became aware that weather forecasting might develop into a reality as a result of the invention of the electric telegraph. Great discoveries were made : Buys Ballot announced one of them in the form of four propositions during a meeting of the Netherlands Academy of Sciences (October 3, 1857), and it was on the basis of these four propositions that later on the famous wind law of Buys Ballot was formulated. Weather maps, though rather primitive, were drawn by Buys Ballot on a routine basis, and a gale warning service was established in 1864. Internationally minded as he was, Buys Ballot copied the system of signals already in use in Britain; but when the British service was discontinued in 1866, he felt free to develop the 'aëroclinoscope', a new design to indicate forthcoming gales to sailors. The aëroclinoscope was a signal post, which showed the direction and value of the pressure gradient over the Netherlands. Its indications had therefore to be interpreted by the users, who had to have a thorough idea of Buys Ballot's law. This might be one of the reasons why the Dutch merchant marine became so early thoroughly interested in meteorology and assisted the Institute in building up an enormous amount of material, gathered from almost every ocean.

It is worth noting that Buys Ballot needed continuous registration of the pressure values at several stations in order to be able to follow the gradients closely. The first electric telerecorders, precursors of our radiosondes, were then developed and for some time serious efforts were made to record at Utrecht the pressure values at Flushing during the night hours. The technical difficulties appeared to be very great, and finally the efforts were given up. It is still, however, customary in the Dutch synoptic service to compute the pressure gradient in various triangles over the Netherlands on an hourly routine basis.

Buys Ballot needed uniform observations for the successful realization of his programme. The wellknown international congress in Brussels (1853), which was initiated by Maury, created a certain uniformity in maritime meteorology; over land, however, observations were made at different times, with different instruments in varying exposure. The difficulties resulting from the lack of generally 